\title{
An experimental investigation on the water retention behaviour of a silty soil for the computation of the lateral earth thrust on a retaining wall
}

\author{
Gianluca Speranza ${ }^{1,2, *}$, Alessio Ferrari ${ }^{1}$, Maxime Pousse $^{2}$, and Lyesse Laloui ${ }^{1}$ \\ ${ }^{1}$ EPF Lausanne, Department of Civil Engineering,.CH-1015, Lausanne, Switzerland \\ ${ }^{2}$ Nobatek/INEF4, F-64600 Anglet, France
}

\begin{abstract}
Retaining structures often interact with soils in unsaturated conditions and their performance is influenced by environmental actions. Currently, geotechnical analysis and design approaches mainly consider the soils either totally dry or totally saturated. Environmental actions, like infiltration due to rainfall, can significantly affect the lateral earth pressure of soils, influencing the performance of both temporary or permanent retaining structures. This paper deals with the investigation of the water retention behaviour of a silty soil for the computation of the soil thrust on a retaining wall during rainfall events. In this regard, the retention property of the involved geomaterial is investigated in laboratory through the combined use of high capacity tensiometers (HCT) and a dew-point hygrometer (WP4C). Considering drying and wetting paths, the experimental results are employed to calibrate the water retention behaviour for the computation of the failure shear strength of the geomaterial. The importance to monitor volume change during the characterization of the water retention behaviour of fine soils is highlighted. A series of analytical uncoupled hydromechanical analyses is performed to estimate the changing in the thrust of an unsaturated soil on a retaining wall under several infiltration rates. An appropriate modelling of the soil water retention behaviour is resulted to be crucial for the computation of lateral earth thrust.
\end{abstract}

\section{Introduction}

Retaining structures often retain soils that are in partially saturated conditions and, these conditions may be present during part or all of their design life [1]. Regardless, their performance is influenced by the environmental actions. Rainfall events can induce significant changes in the resulting thrust on the geostructures. Current geotechnical procedures consider the soils either totally dry or totally saturated. The latter condition can lead to a non-optimized design of the retaining structures [2].

During drying periods, evaporations occur in the retained soils, as a consequence, the shear strength of the geomaterial increases due to the increase of matric suction, inducing a reduction of the thrust on the retaining structures. On the other hand, during wetting periods, the infiltration rates lead to a reduction of the matric suction resulting in an increase of the lateral earth thrust. In this regard, the characterization of the water retention behaviour of the involved soils plays a fundamental role. Indeed, the water retention behaviour controls the infiltration through the dependency of the hydraulic conductivity on the degree of saturation (and then on suction). In general, the analysis of the earth thrust for un unsaturated soil can be performed by considering the influence of suction on the shear strength, and this can be achieved by computing the effective stress considering the product between suction and degree of saturation (see section 2.1). In this work, the retention properties of a silty soil are investigated through a laboratory experimental programme. The experimental steps to characterize the water retention behaviour of the tested soil are described. Both wetting and drying path are investigated through the combined use of high capacity tensiometers (HCT) and a dew-point hygrometer (WP4C).

The water retention properties of soils depend on void ratio e.g. [3], for this reason the volume changes of the specimens are assessed by a photogrammetric technique. The achieved experimental results are employed for the modelling of the water retention behaviour of the tested soil and then to compute the available shear strength. A series of analytical uncoupled hydro-mechanical analyses has been performed and the effects of infiltration on the earth thrust are considered by performing steady state analyses. Rankine's theory and Coulomb's method are employed to estimate the lateral earth thrust of unsaturated soils on the retaining structure at different seepage rates.

* Corresponding author: gianluca.speranza@epfl.ch 


\section{Materials and methods}

\subsection{The computation of the lateral earth thrust for unsaturated soils}

In the literature, examples showing the interactional behaviour between retaining structures and unsaturated soils can be found in [4-7]. These works have mainly provided the extension of the classical theories (i.e. Rankine's theory and Coulomb's method) for the estimate of the lateral earth thrust taking into account Unsaturated Soil Mechanics principles. These approaches are here employed for the computation of the lateral earth thrust acting on the retaining structure reported in Fig.1. The height of the considered retaining wall is $4 \mathrm{~m}$ and is imposed equal to the depth of the groundwater table (Y).

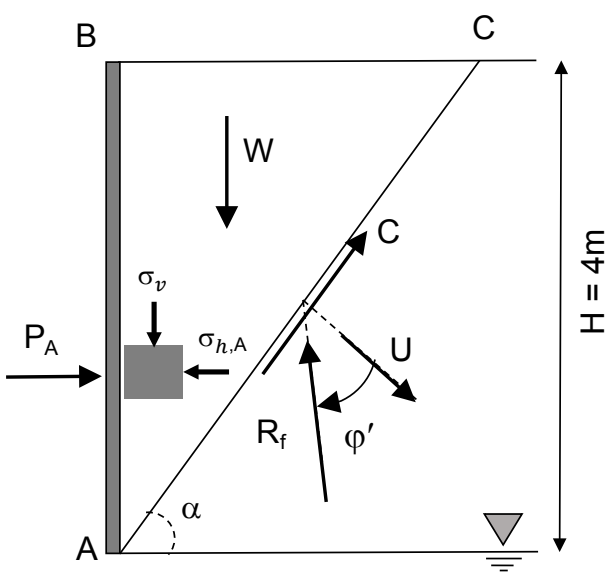

Fig. 1 Geometry of the investigated problem.

Selecting an adequate effective stress definition, it is possible to compute the available shear strength at failure $\left(\tau_{f}\right)$. Here, the generalized effective stress [8] is selected among the others available in the literature:

$$
\sigma_{i j}^{\prime}=\left(\sigma_{i j}-u_{a} \delta_{i j}\right)+S_{r}\left(u_{a}-u_{w}\right) \delta_{i j}
$$

where $\sigma^{\prime}{ }_{\mathrm{ij}}$ is the effective stress tensor, $\sigma_{\mathrm{ij}}$ is the total stress tensor, $S_{r}$ is the degree of saturation, $u_{a}$ is the air pressure, $\mathrm{u}_{\mathrm{w}}$ is the water pressure and $\delta_{\mathrm{ij}}$ the Kronecker's delta.

The available shear strength on the failure plane can be then computed as

$$
\tau_{f}=c^{\prime}+\left[\left(\sigma_{n}-u_{a}\right)+S_{r}\left(u_{a}-u_{w}\right)\right] \tan \varphi^{\prime}
$$

where $\sigma_{\mathrm{n}}$ is the total stress acting perpendicular to the considered plane, $\mathrm{c}^{\prime}$ and $\varphi^{\prime}$ are respectively the intercept cohesion and the shear strength angle. Starting from the shear strength of the material it is possible to extend the classical theory of lateral earth thrust to unsaturated soils. For the active case, the resulting thrust $\left(\mathrm{P}_{\mathrm{A}}\right)$ computed according to the Coulomb's methods can be derived:

$$
P_{A}=\frac{W \sin \left(\alpha-\varphi^{\prime}\right)-C \cos \varphi^{\prime}-U \sin \varphi^{\prime}}{\cos \left(\alpha-\varphi^{\prime}\right)}
$$

where $\mathrm{W}$ is the weight of the sliding block, while $\mathrm{C}$ and $\mathrm{U}$ are respectively the resultant of the cohesion and the contribute provided by the matric suction along the failure surface. The latter can be computed as follows:

$$
U=\frac{1}{\sin \alpha} \int_{0}^{H} S_{r}\left(u_{a}-u_{w}\right) d z
$$

While, the lateral earth pressure according to Rankine's theory can be computed as follows:

$$
\sigma_{h, A}-u_{a}=\left(\sigma_{v}-u_{a}\right) K_{A}-2 c^{\prime} \sqrt{K_{A}}-S_{r}\left(u_{a}-u_{w}\right)\left(1-K_{A}\right)
$$

where $\sigma_{\mathrm{h}, \mathrm{A}}$ is the active total lateral earth pressure, $\sigma_{\mathrm{v}}$ the vertical total stress and $\mathrm{K}_{\mathrm{A}}$ the active earth pressure coefficient defined as follows:

$$
K_{A}=\tan ^{2}\left(\frac{\pi}{4}-\frac{\varphi^{\prime}}{2}\right)
$$

It is important to highlight that the two methods are comparable only in the condition of the validity of the Rankine's theory. In particular, the soil-structure friction is not considered in the present work.

As introduced before, during wetting periods, the infiltration rates lead to a reduction of the matric suction resulting in an increase of the lateral earth thrust. For this reason, infiltration analyses have to be performed. According to $[4,6,7]$, the evolution over depth (z) of the matric suction at constant infiltration rate (i) can be achieved coupling the Darcy's law with an exponential model of the hydraulic conductivity [9]:

$$
\left(u_{a}-u_{w}\right)=-\frac{1}{\alpha_{w}} \ln \left[\left(1+\frac{i}{k_{s}}\right) e^{-\gamma_{w} \alpha_{w}(Y-z)}-\frac{i}{k_{s}}\right]
$$

where $\mathrm{k}_{\mathrm{s}}$ is the saturated hydraulic conductivity, $\gamma_{\mathrm{w}}$ the water specific weight and $\alpha_{w}$ the calibration parameter of the exponential model of the hydraulic conductivity

Once the hydraulic part of the model is solved, the achieved matric suction distribution is employed for the computation of the lateral earth thrust of the retained soil. The modelling of the retention behaviour of the soil plays a crucial role. For this reason, it has been decided to investigate the water retention behaviour of a silty soil, evaluating the effect on the shear strength and on the active lateral earth thrust.

\subsection{The investigated soil}

The material tested in the laboratory is the Sion Silt characterized by $72 \%$ of silt, $20 \%$ of sand and $8 \%$ of clay, and it can be classified as a clayey sandy silt (CL/ML) in the Unified Soil Classification System (USCS). Table 1 summarizes some features of the soil where $\rho_{\mathrm{s}}$ is the solid density, $\mathrm{w}_{\mathrm{l}}$ and $\mathrm{w}_{\mathrm{p}}$ are respectively the liquid limit and plastic limit.

Previous works (e.g. [10]) investigated the mineralogy of the clay fraction concluding that the geomaterial can be considered as non-swelling material. The intercept 
cohesion and the shear strength angle are equal to 0 and $32^{\circ}$ respectively.

Table 1. Soil parameters.

\begin{tabular}{|c|c|c|c|c|}
\hline $\begin{array}{c}\rho_{s} \\
\left(\mathbf{g} / \mathbf{c m}^{3}\right)\end{array}$ & $\begin{array}{c}w_{p} \\
(\%)\end{array}$ & $\begin{array}{c}w_{l} \\
(\%)\end{array}$ & $\begin{array}{c}\boldsymbol{c}^{\prime} \\
(\boldsymbol{k P a})\end{array}$ & $\begin{array}{c}\boldsymbol{\varphi}^{\prime} \\
(\boldsymbol{\%})\end{array}$ \\
\hline 2.7 & 16.7 & 25.4 & 0 & 32 \\
\hline
\end{tabular}

\subsection{Experimental determination of the water retention curve}

The soil has been compacted in a conventional Proctor apparatus to produce several specimens characterized by the same void ratio. An initial sample was created with an initial water content $\left(\mathrm{w}_{0}\right)$ of $21.1 \%$ and an initial void ratio $\left(\mathrm{e}_{0}\right)$ equal to 0.63 (average of the specimens). Afterwards, the specimens were extruded from the sample and placed in $60 \mathrm{~mm}$ diameter (D) and $15 \mathrm{~mm}$ height (h) rings. The bottom of the rings was closed with a filter paper and the top of the specimens was carefully smoothed. The specimens were covered with a plastic cover to prevent evaporation from the top and they were placed in a box partially filled with water to saturate them via capillary rise.

The experimental setup (Fig.2) is characterized by: an electronic balance (resolution of $0.01 \mathrm{~g}$ ), a series of HCTs, a HCTs' saturation chamber connected to a pressure volume controller, a data acquisition system for the HCTs, a digital camera fixed on a still frame placed above the electronic scale. On the scale, a circular plastic container was glued to host one of the specimens to record the change in water mass during both drying and wetting paths. A second similar container was employed to host a second specimen, to record the evolution of matric suction. In this regard, a hole at the bottom of the second container was created in order to allow the hydraulic contact between the ceramic of the HCT and the specimen. The surface contact between the HCT and the container was sealed with a mastic paste during the experiments in order to prevent water leaks or preferential evaporation channels. The employed HCTs are described in [11]. The HCTs are calibrated in the positive range of water pressure. The positive pressure was applied through the pressure/volume controller connected to the saturation chamber where HCTs were allocated. A discussion about the limits of this calibration methods can be found in [12]. HCTs are capable to measure matric suction theoretically up to the ceramic air entry value $(1500 \mathrm{kPa})$, even if cavitation after the test has happened for a suction value higher than $2000 \mathrm{kPa}$.

Moreover, to explore the water retention behaviour of the tested soil at higher suction values, a third specimen has been initially subjected to the same paths as the other two and after, WP4C was used to record higher suction values (total suction in this case). Two tests have been performed simulating both drying and wetting paths. The drying path was simulating leaving the three specimens in contact with the laboratory atmosphere. This method, also known as "continuous drying", has been investigated by [13-14].
An overestimation of suction values is possible especially if the tensiometer is placed at the evaporation surface. This is because while the evaporation happens, the whole specimen has not time to get the equilibrium. For this reason, it has been decided to place the tensiometer at the bottom of the specimen. A different method, known as "drying by step", can be applied preventing continuous evaporation and allowing the specimen to get the equilibrium [13]. As it will be discussed after in the paper, the soil water retention model needed for the modelling of the seepage is related to the wetting path; for this reason, it has been decided to adopt a continuous drying method and a wetting by step method for the present experiment.

A first test has been performed drying two specimens up to almost $1000 \mathrm{kPa}$. The matric suction was recorded in one specimen while the changes in water content were measured in the other. At different time steps, pictures were taken in order to monitor changes in volume. Fig. 3 shows the evolution of the matric suction with time during the drying path. Shrinkage of the specimen could be observed with the naked eye.

At $1000 \mathrm{kPa}$ the wetting path was started and the whole amount of the evaporated water was added in ten steps in both the specimens with a syringe. As mentioned before, during each step, evaporation was prevented covering the specimens allowing for the equalization. Fig.4 shows the evolution of the matric suction during the wetting path.

The test was repeated (Test2) involving three specimens. Matric suction was recorded up to the cavitation of the tensiometer while, the specimens have been exposed to

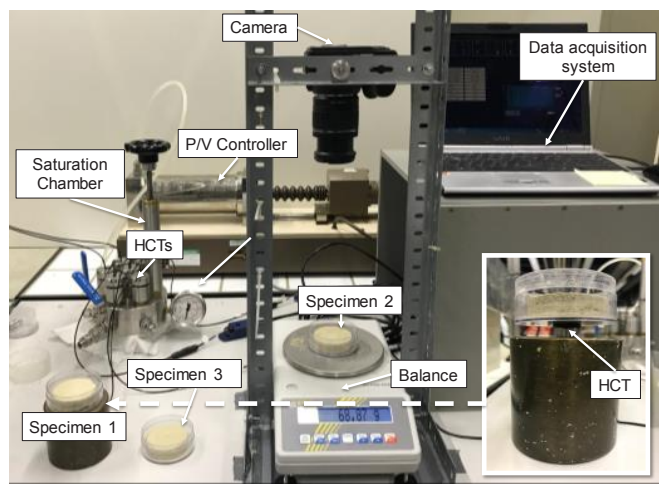

Fig. 2. View of the experiment setup.

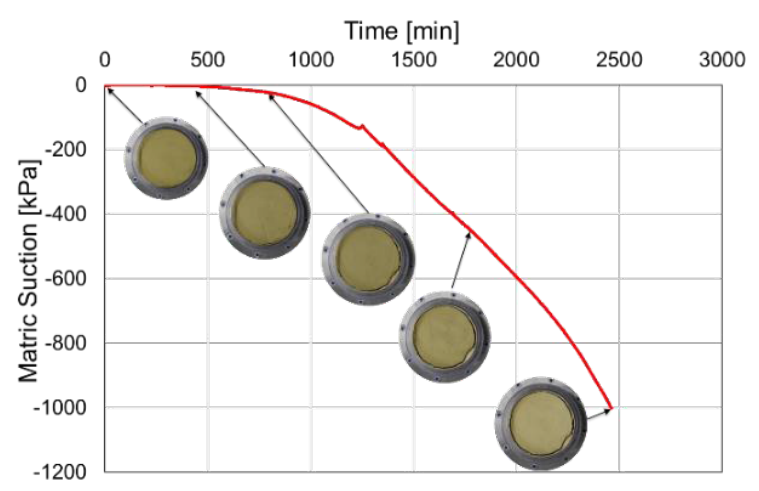

Fig. 3. Matric suction evolution with time, wetting - Test1. 


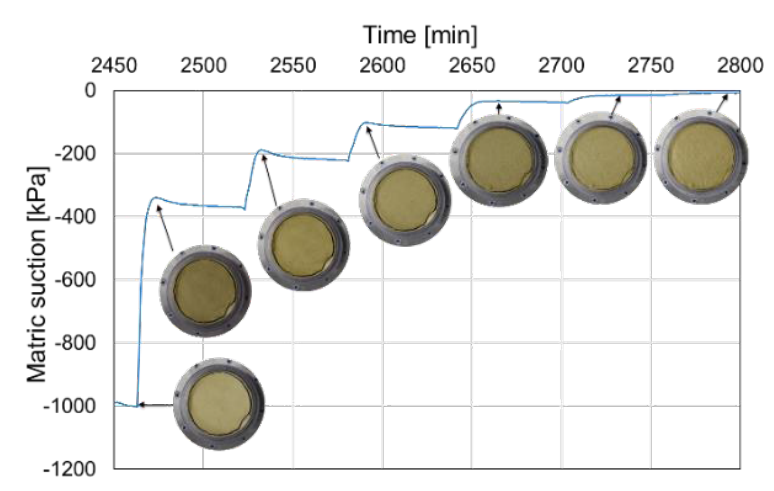

Fig. 4 Matric suction evolution with time, drying - Test1.

the laboratory atmosphere for few days in order to get them close to the residual water content. A part of the third specimen was prepared to be placed in the WP4C. A similar approach can be found in [15]. The wetting path was started again but values of matric suction could be recorded only once they were inside the operative range of the HCTs.

Also during the wetting path volume changes could be easily noticed. In this regard, deformation records are needed to follow the evolution of the degree of saturation The pictures from the top were analysed via a photogrammetric technique, and the changes of the average diameter were measured.

The resolution of this method has been estimated to be around $0.1 \mathrm{~mm}$. Fig.5, shows some examples of the shrinkage and swelling of a specimen observed during the experiments.

The assumption of isotropic behaviour is done in order to get the changes in volume. It is assumed that, for each step, the radial deformation is equal to the vertical.

\section{Results and discussion}

The performed experiments have allowed to characterize the water retention behaviour and to get the shrinkage and the swelling curve of the investigated soil. The results, presented in the next subsections, are analysed in the framework of the lateral earth pressure for unsaturated soils under rainfall events. Moreover, they are needed to identify some key parameters to perform steady state hydro-mechanical analyses.

\subsection{The water retention behaviour}

In Fig. 6 the results of the tests are reported in terms of degree of saturation and suction. They are plotted in terms of suction, since data referring to HCTs correspond to matric suction while WP4C data correspond to total suction. The overlap with the two techniques suggest that osmotic suction is marginal.

The experimental results have been fitted via a Van Genuchten [16] model for both the main drying and the main wetting curve:

$$
S_{r}=\left(\frac{1}{\left(1+\left[\alpha\left(u_{a}-u_{w}\right)^{n}\right]\right.}\right)^{m}
$$

The parameters of the fitting models for wetting and drying paths are summarized in table 2 .

Fig. 7 shows the shrinkage and the swelling curve for Test 1 . It is possible to observe that the majority of the deformation happens before the air entry value and the

Table 2. Parameters of the Van Genuchten fitting models.

\begin{tabular}{|c|c|c|c|c|c|}
\hline $\begin{array}{c}\boldsymbol{\alpha}_{\boldsymbol{d}} \\
\left(\boldsymbol{k P a}^{-1}\right)\end{array}$ & $\begin{array}{c}\boldsymbol{n}_{\boldsymbol{d}} \\
(-)\end{array}$ & $\begin{array}{c}\boldsymbol{m}_{\boldsymbol{d}} \\
(-)\end{array}$ & $\begin{array}{c}\boldsymbol{\alpha}_{w} \\
\left(\boldsymbol{k P a}^{-1}\right)\end{array}$ & $\begin{array}{c}\boldsymbol{n}_{\boldsymbol{w}} \\
(-)\end{array}$ & $\begin{array}{r}\boldsymbol{m}_{\boldsymbol{w}} \\
(-)\end{array}$ \\
\hline $9.910^{-4}$ & 0.96 & 1.93 & $6.710^{-4}$ & 0.50 & 1.98 \\
\hline
\end{tabular}

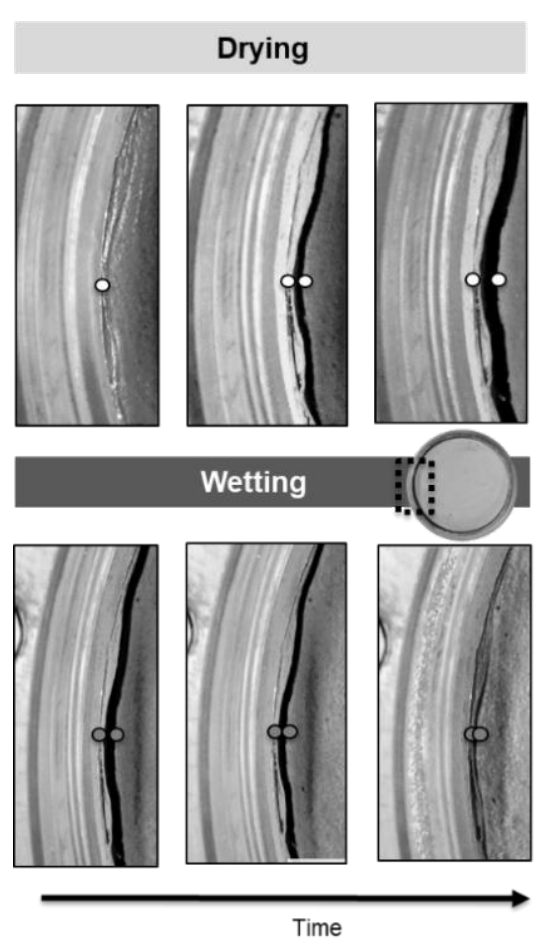

Fig. 5. Shrinkage and swelling during drying and wetting paths, zoom on the specimen border.

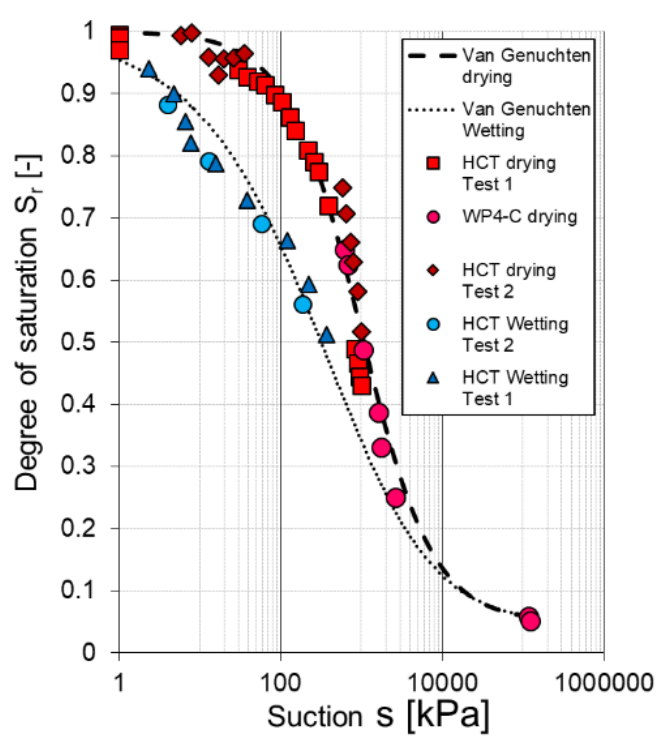

Fig. 6. Experimental results and fitting with a Van Genuchten model. 
shrinkage limit is achieved after few hundreds of $\mathrm{kPa}$. For this reason, high suction values measured with the WP4C have been associated to the degree of saturation considering the volume of the specimens at the shrinkage limit.

Moreover, the swelling curve has shown that the initial void ratio is not totally recovered during wetting.

Trying to interpret the results in the framework of the performance of a retaining wall in unsaturated soils, it is possible to observe that during wetting and drying periods, the retained soils would be subjected to the hysteretic behaviour well shown in Fig.6. More likely, during longer or shorter drying periods, the suction will reach respectively higher or lower values. Depending on the starting point of the wetting path, the relation between the degree of saturation and the suction could follow either a scanning wetting curve or the main wetting curve.

\subsection{Impact of the water retention behaviour on the shear strength and the lateral earth thrust}

The computation of the lateral earth thrust of unsaturated soils during rainfall events is influenced by the choice of the model that describe the water retention behaviour. In particular, it will affect both the hydraulic and the mechanical step of the analysis. In this regard, Fig.8 shows the evolution of the failure shear strength of the investigated soil with the suction. Three reasonable vertical net stress values were chosen compatibly with the dimensions of the involved case study. It is immediately noticeable that the failure shear strength adopting the main drying Van Genuchten curve is always higher than that obtained with the main wetting curve. As a consequence, the lateral earth actions will result in higher values. Modelling analytically a scanning wetting path the analysis will be placed in the middle of this two scenarios.

Moreover, infiltration rate plays a crucial role. Fig.9a and Fig.9b show the evolution over the depth of the degree of saturation and the matric suction for different infiltration rates respectively. If the infiltration rate is imposed equal to the saturated hydraulic conductivity the resulting lateral earth actions are higher than those of the soil considered totally dry and lower than the soil considered totally saturated with ground water table at the top of the geostructures. Fig.9d, shows the comparison between the integral of the lateral earth pressure distribution (Fig.9c) achieved following the Rankine's theory and the resultant force calculated via the Coulomb's method (it corresponds to the maximum value of the parabola). Focusing on the condition of the soil either totally dry or totally saturated the Rankine theory and the Coulomb's methods leads exactly to the same results. Under infiltration rates lower than the saturated hydraulic conductivity, the Coulomb's method provides lower thrust values. This is due to the fact that, if the lateral earth pressure is computed according to the Rankine's theory, only positive values are considered because a negative value will result in a pulling of the geostructure toward the retained soil which would be a physically not acceptable.

\section{Summary and conclusions}

In this work the retention properties of a silty soil were studied via laboratory experimental analysis. Both drying and wetting path were investigated.

The HCTs are confirmed to be a good tool for a direct measurement of the matric suction in their operative range. To well characterize the water retention behaviour of fine soils the measure of volume changes is crucial especially before the air entry suction value.

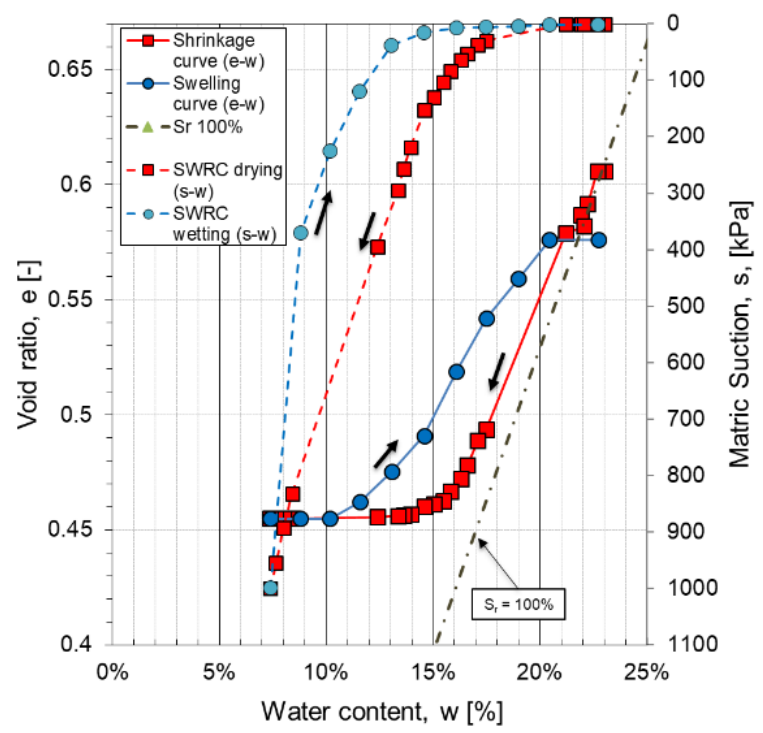

Fig. 7. Shrinkage and swelling curve, Test1.

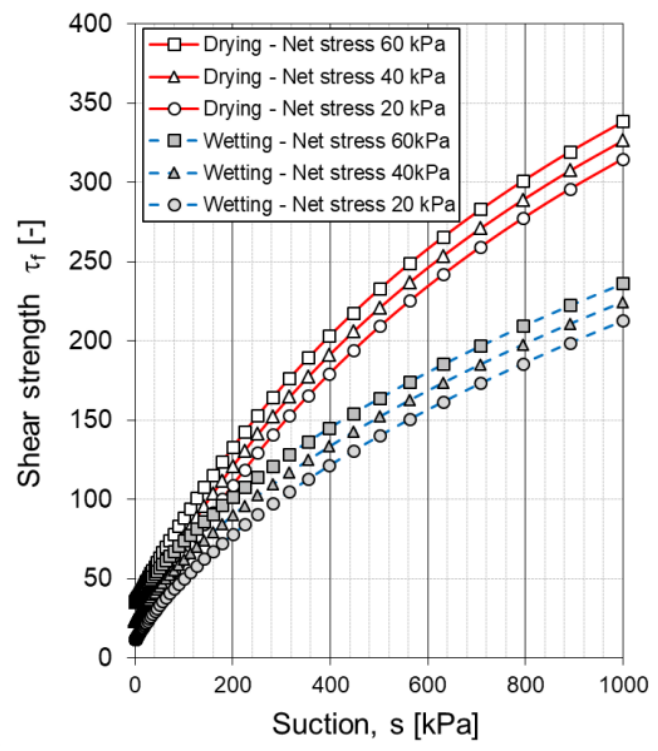

Fig. 8. Evolution of shear strength with suction at different net stress.

The achieved results have been employed for the implementation of a closed form analytical hydromechanical analyses.

Despite the important assumptions, the results have shown that attention must be paid in the choice of the soil parameters when Unsaturated Soil Mechanics principles are employed in geotechnical analyses. The behaviour of unsaturated soils is hysteretic under drying and wetting 
paths and it should be taken into account in geoengineering applications.

Anyway, more sophisticated fully coupled hydromechanical analyses are needed to better understand the interaction between unsaturated soils and retaining structures during both drying and wetting periods.
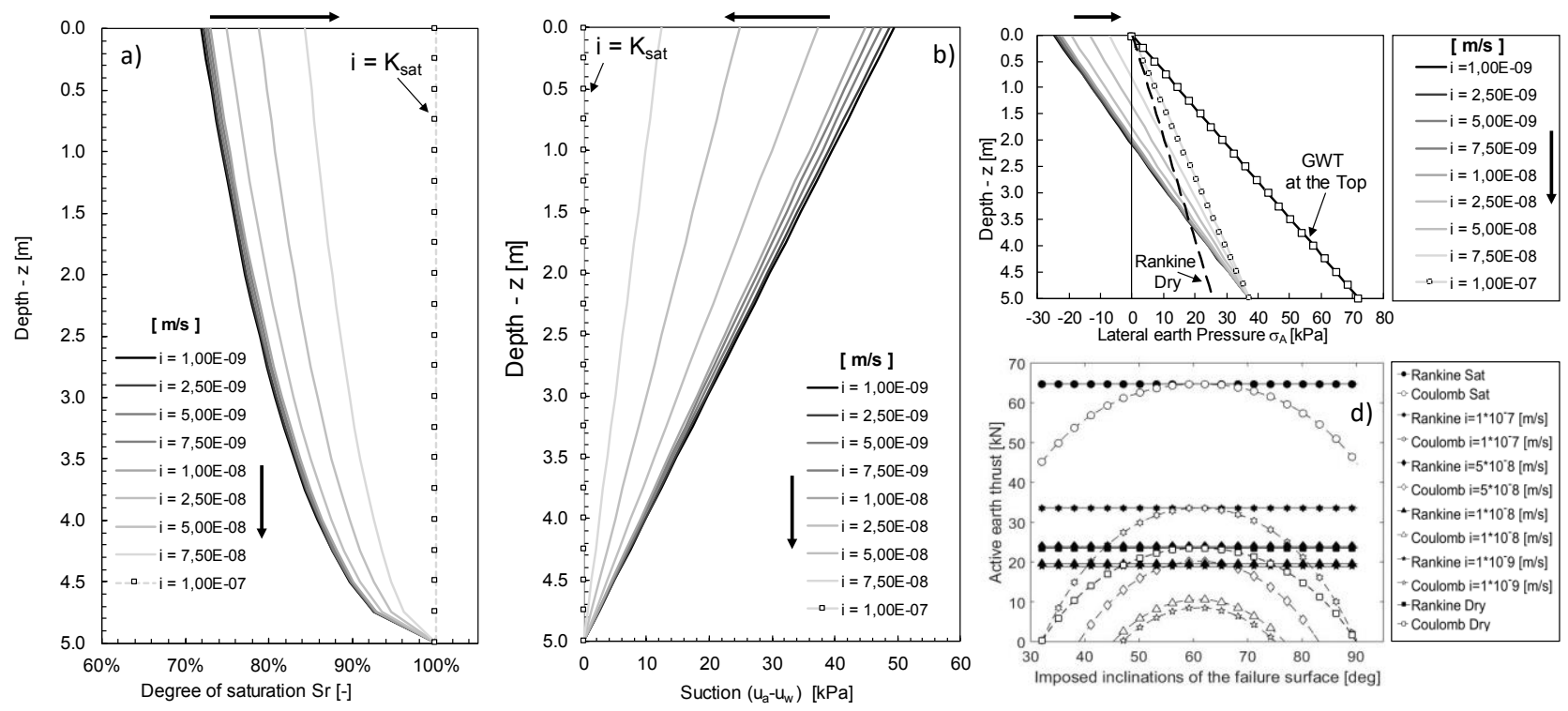

Fig.9 a) Evolution of degree of saturation with depth at differ infiltration rates, b) evolution of suction at different infiltration rates, c) lateral earth pressure distribution for dry, unsaturated and saturated case, d) comparison between Coulomb and Rankine's method.

The authors wish to acknowledge the support of the European Commission via the Marie Skłodowska-Curie Innovative Training Networks (ITN-ETN) project TERRE 'Training Engineers and Researchers to Rethink Geotechnical Engineering for a low carbon future' (H2020-MSCA-ITN-2015675762).

\section{References}

1. G. A. Siemens, Thirty-ninth Canadian Geotechnical Colloquium: Unsaturated Soil Mechanics: Bridging the Gap Between Research and Practice. Canadian Geotechnical Journal, 55.7, pp 909-927, (2017)

2. A. Harris, A.J. Bond, Decoding Eurocodes, CRC Press, (2006)

3. A. C. Farulla C., A. Battiato, A. Ferrari, The void ratio dependency of the retention behaviour for a compacted clay, in Unsaturated Soils - Proceedings of the 5th International Conference on Unsaturated Soils; Barcelona; Spain; 6 - 8 September 2010, vol.1, pp. 417-422, (2010).

4. N. Lu, W. J. Likos, Unsaturated Soil Mechanics. Wiley, (2004)

5. D. G Fredlund,. H. Rahardjo, H. Rahardjo, Soil mechanics for unsaturated soils. John Wiley \& Sons, (1993)

6. F. Vahedifard, B. A. Leshchinsky, K. Mortezaei, N. Lu, Active earth pressures for unsaturated retaining structures. Journal of Geotechnical and Geoenvironmental Engineering, 141.11, (2015)

7. J. P. Sahoo, R. Ganesh, International Congress and Exhibition" Sustainable Civil Infrastructures: Innovative Infrastructure Geotechnology pp. 1-19, (2017)

8. M. Nuth,, L. Laloui, Effective stress concept in unsaturated soils: clarification and validation of a unified framework. International journal for numerical and analytical methods in Geomechanics, 32.7, 771-801, (2008)

9. W. R. Gardner, Some steady state solutions of the unsaturated moisture flow equation with application to evaporation from a water table, Soil Science 11, pp 215 232, (1958)

10. F. Geiser, Ph. D. thesis, Comportement mécanique d'un limon non saturé étude expérimentale et modélisation constitutive, (1999)

11. A. Tarantino, L. Mongiovì, Design and construction of a tensiometer for direct measurement of matric suction. Proceedings $3^{\text {rd }}$ International Conference on Unsaturated Soils, pp 319-324, (2002)

12. A. Tarantino, L. Mongiovi, Calibration of tensiometer for direct measurement of matric suction, Géotechnique 53.1, (2003)

13. S.D.N. Lourenco, D. Gallipoli, D.G. Toll, C.E. Augarde, and F.D. Evans. A new procedure for the determination of soil water retention curves by continuous drying using high-suction tensiometers Canadian Geotechnical Journal, 48.2, pp 327-335, (2011)

14. S.D.N. Lourenco, D. Gallipoli, D.G. Toll, F.D. Evans, G.M. Medero. Determination of the Soil Water Retention Curve with Tensiometers, in Schanz, T. (Ed.), Experimental Unsaturated Soil Mechanics. SpringerVerlag, Berlin, pp. 95-102, (2007)

15. A Ferrari, V. Favero, P. Marschall, L. Laloui, Experimental analysis of the water retention behavior of shales. International Journal of Rock Mechanics \& Mining Sciences, 72, pp 61-70, (2014)

16. M. Van Genuchten, A closed-form equation for predicting the hydraulic conductivity of unsaturated soils. Soil science society of America journal, 44.5, pp. 892-898, (1980) 